\title{
Evaluación de susceptibilidad en cándidas spp por colorimetría obtenida en gestantes de un hospital obstétrico
}

\author{
Susceptibility evaluation in candida spp by colorimetry obtained in pregnant women from an \\ obstetric hospital
}

\section{Avaliação da suscetibilidade em cândida spp por colorimetria obtida em gestantes de um hospital obstétrico}

\author{
Marly Katherine Ávila Tandazo \\ mavilatandazo@gmail.com \\ ORCID: 0000-0002-8095-1281
}

\author{
Anny Gabriela Villacís Villacís \\ annygab.94@hotmail.com \\ ORCID: 0000-0002-6271-2762
}

\section{Carmen Silverio \\ csilverio@utmachala.edu.ec \\ ORCID: 0000-0003-3587-4149}

Universidad Técnica de Machala, Ecuador

\begin{abstract}
RESUMEN
Introducción: Las infecciones fúngicas ocasionadas por levaduras del género Cándida son extremadamente comunes en mujeres de edad reproductiva, y constituyen un motivo de atención medica de salud. Objetivo: evaluar la susceptibilidad de Cándidas spp, mediante el método colorimétrico (Integral Yeast System Plus). Método: fue de tipo descriptivo, transversal; se recopiló información mediante observación directa en campo y el análisis documental para obtener información bibliográfica de tipo secundaria. Resultados: De los 72 casos encontrados de Cándida Albicans revela que son susceptibles a la anfotericina B $(2 \mathrm{ug} / \mathrm{ml})$; de los 5 casos encontrados de Cándida Krusei revela que son sensibles a la Anfotericina B $(2 \mathrm{ug} / \mathrm{ml})$; De 1 caso encontrado de Cándida Parapsilosis revela sensibilidad en la Nistatina $(1.25 \mathrm{ug} / \mathrm{ml})$. En este estudio la prevalencia de la infección por Cándida fue del (44.98\%). Conclusiones: Cándida Albicans fue la especie más común aislada en las mujeres embarazadas representando un $72 \%$, En la evaluación de la susceptibilidad a través del kit Integral System Yeast Plus se obtuvo que Cándida Albicans es susceptible a Anfotericina B, Flucitosina entre otros, en Cándida Glabrata se obtuvo que es sensible a la Nistatina, Anfotericina B, susceptible entre otros, en Cándida Krusei se obtuvo que es sensible a la Anfotericina B, Clotrimazol, Miconazol, susceptibles a la Nistatina, Voriconazol y resistente a la Flucitosina, Ketoconazol, Itraconazol y Fluconazol.
\end{abstract}

Palabras clave: susceptibilidad en cándida; colorimetría, gestante

\begin{abstract}
Introduction: Fungal infections caused by yeast of the genus Candida are extremely common in women of reproductive age, and constitute a reason for medical health care. Objective: to evaluate the susceptibility of Candida spp, using the colorimetric method (Integral Yeast System Plus). Method: it was descriptive, transversal; Information was collected through direct observation in the field and documentary analysis to obtain secondary bibliographic information. Results: Of the 72 cases found, Candida Albicans reveals that they are susceptible to amphotericin B (2ug / $\mathrm{ml})$; of the 5 cases found, Candida Krusei reveals that they are sensitive to Amphotericin B (2ug / ml); Of 1 case found of Candida Parapsilosis reveals sensitivity in Nystatin $(1.25 \mathrm{ug} / \mathrm{ml})$. In this study, the prevalence of Candida infection was (44.98\%). Conclusions: Candida Albicans was the most common species isolated in pregnant women, representing $72 \%$. In the evaluation of susceptibility through the Integral System Yeast Plus kit it was obtained that Candida Albicans is susceptible to Amphotericin B, Flucytosine among others, in Candida Glabrata was obtained that it is sensitive to Nystatin, Amphotericin B, susceptible among others, in Candida Krusei it was obtained that it is sensitive to Amphotericin B, Clotrimazole, Miconazole, susceptible to Nystatin, Voriconazole and resistant to Flucytosin, Ketoconazole, Itraconazole and Fluconazole
\end{abstract}

MA: Maestría en Bioquímica Farmacéutica. Laboratorio Clínico Biomedilab 2017. Bacteriología Hospital Obstétrico Ángela Loayza de Ollague 2019. Analista distrital de medicamentos y dispositivos médicos 2020. Universidad Técnica de Machala, Ecuador.

AV: Maestría en Bioquímica Farmacéutica de la Universidad Técnica de Machala. Actualmente trabaja en Laboratorio Biomedilab, Hospital Obstétrico Ángela Loayza de Ollague. Universidad Técnica de Machala, Ecuador.

CS: Bioquímica Farmacéutica, profesora titular de la Universidad Técnica de Machala, 46 años, máster en Biotecnología molecular, máster en Salud con enfoque ecosistémico (Convenio marco Universidad ecosistémico (Convenio marco Universidad
British Columbia-Universidad Técnica de Machala), máster en docencia universitaria, formación académica y experiencia en laboratorio Microbiología, Análisis Clínico, profesora de Microbiología y Biotecnología Molecular, en el área de investigación tutora de investigaciones científicas en la carrera de Bioquímica y Farmacia, Machala, EL ORO, ECUADOR.

Key words: susceptibility in candida; colorimetry, pregnant 
MA: Maestría en Bioquímica Farmacéutica. Laboratorio Clínico Biomedilab 2017 Bacteriología Hospital Obstétrico Ángela Loayza de Ollague 2019. Analista distrital de medicamentos y dispositivos médicos 2020 Universidad Técnica de Machala, Ecuador.

AV: Maestría en Bioquímica Farmacéutica de la Universidad Técnica de Machala Actualmente trabaja en Laboratorio Biomedilab, Hospital Obstétrico Ángela Loayza de Ollague. Universidad Técnica de Machala, Ecuador.

CS: Maestría en Bioquímica Farmacéutica y Auxiliar de Enfermería en Experiencia Laboral. En 2019 Bioquímica Farmacéutica en el Hospital Ángela Loayza de Ollague y en 2020 Bioquímica Farmacéutica Laboratorio Biomédica Universidad Técnica de Machala Techala Ecuador

\section{RESUMO}

Introdução: As infecções fúngicas causadas por leveduras do gênero Candida são extremamente comuns em mulheres em idade reprodutiva e constituem motivo de cuidados médicos. Objetivo: avaliar a suscetibilidade de Candida spp, por meio do método colorimétrico (Integral Yeast System Plus). Método: foi descritivo, transversal; as informações foram coletadas por meio de observação direta em campo e análise documental para obtenção de informações bibliográficas secundárias. Resultados: Dos 72 casos encontrados, Cândida Albicans revelou ser suscetíveis à anfotericina B (2ug / $\mathrm{ml}$ ); dos 5 casos encontrados, Candida Krusei revela que são sensíveis à Anfotericina B (2ug / ml); de 1 caso encontrado de Candida Parapsilosis revela sensibilidade na Nistatina $(1,25 \mathrm{ug} / \mathrm{ml})$. Neste estudo, a prevalência de infecção por Candida foi (44,98\%). Conclusões: Cândida Albicans foi a espécie mais comum isolada em gestantes, representando $72 \%$. $\mathrm{Na}$ avaliação da susceptibilidade através do kit Integral System Yeast Plus foi obtido que Candida Albicans é suscetível à Anfotericina B, Flucitosina entre outras, em Cândida Glabrata foi obtido que é sensível a Nistatina, Anfotericina B, suscetível entre outras, em Candida Krusei foi obtido que é sensível a Anfotericina B, Clotrimazol, Miconazol, suscetível a Nistatina, Voriconazol e resistente a Flucitosina, Cetoconazol, Itraconazol e Fluconazol

Palavras-chave: susceptibilidade em cândida; colorimetria, grávida

\section{INTRODUCCIÓN}

$\mathrm{L}$ as infecciones fúngicas ocasionadas por levaduras del género Cándida son extremadamente comunes en mujeres de edad reproductiva, y constituyen un motivo de atención medica de salud (1), representando un $15-20 \%$ en consultas ginecológicas(2).

En el tercer trimestre de gestación puede elevarse la prevalencia de candidiasis en comparación con las mujeres no gestantes debido a una elevación de niveles de estrógeno. Según la Organización Mundial de Salud (2015) cada día 1 millón de personas adquieren una infección de trasmisión sexual (3). Se considera que más de 300 millones de personas de todas las edades sufren una infección fúngica grave cada año en todo el mundo convirtiéndose en un problema de salud (4).

Se estima que el $75 \%$ de todas las mujeres experimentan un episodio de infección vaginal fúngica al menos una vez en su vida (5), el 40-50\% son recurrentes es decir sufren episodios múltiples sintomáticos en tiempo de doce meses(2,5), estas infecciones son ocasionadas por agentes como: bacterias(40-45\%), hongos(20-25\%) y protozoo(15-20\%) $(2,6)$.

En países como Europa a la candidiasis se considera como uno de los motivos más comunes asociados a infecciones en el tracto genital. En países como Estados Unidos y Ecuador es la segunda causa más común de infecciones vaginales representando un $46.1 \%$ (3). La candidiasis recurrente afecta aproximadamente a 307.593 mujeres ecuatorianas de 15 a 50 años (3).

La principal especie implicada en producir candidiasis vaginal es Cándida Albicans responsable de un $80-90 \%$ de los casos (6), aunque también existe un aumento de especies Cándida No albicans que están asociadas con resistencia a ciertos antifúngicos (7).

De tal manera para la identificación precisa de las especies implicadas en la candidiasis junto con la evaluación de la susceptibilidad antimicótica. Se realizará el presente estudio para determinar la suceptibilida de cándida spp mediante método colorimétrico (Integral Yeast System Plus) para evaluar la eficacia de los antimicóticos. 
La ciudad de Santa Rosa en Ecuador posee actualmente una población de 73884 habitantes y cuenta con hospitales que prestan servicios de atención a mujeres embarazadas. En el área de microbiología de uno de estos hospitales se identifican solamente 3 tipos de cándidas: Cándida albicans, Cándida tropicalis, Cándida krusei utilizando el CHROMagar Difco Cándida y 3 antifúngicos para realizar el antibiograma como el Fluconazol, Voriconzacol, Nistatina. Debido a una escases de recursos para la identificación de especies y discos para la susceptibilidad, mediante la realización de la investigación será de aporte a la identificación de cándidas spp, con el método colorimétrico (Integral System Yeast Plus).

El objetivo principal del estudio consiste en evaluar la susceptibilidad de Cándidas spp, mediante el método colorimétrico (Integral Yeast System Plus) para determinar la eficacia de los antimicóticos. A fin de determinar la prevalencia del Género Cándida en gestantes mediante la recolección de datos estadísticos obtenidos en el Hospital objeto de estudio, seguidamente se identifica las especies de cándida spp a partir de muestras vaginales obtenidas de gestantes que acuden al centro hospitalario, logrando con ello, medir la susceptibilidad de Cándida spp por método colorimétrico (Integral System Yeast Plus).

En el objeto de estudio se incluyen secreciones vaginales de mujeres en estado de gestación que acuden al centro hospitalario.

La hipótesis esta relacionada con las muestras de secreción vaginal de gestantes existe presencia de Cándida Albicans, Glabrata, Krusei, Tropicalis, Parapsilosis susceptibles a los antimicóticos por el método colorimétrico. La variable independiente consisten en la prevalencia de Cándidas (Albicans, Glabrata, Krusei,
Tropicalis, Parapsilosis), y la variable dependiente es la evaluación de la susceptibilidad de cándida ante el método colorimétrico (Integral System Yeast Plus).

\section{Marco teórico}

\section{Infecciones de transmisión sexual}

Se definen como un grupo de patologías causadas por agentes infecciosos como bacterias, hongos y virus que se adquieren durante el contacto sexual: vaginal, anal $u$ oral (8). El tracto genital es una entrada para diversas enfermedades de transmisión sexual y no sexual, afectando el sistema reproductor femenino y causando flujo vaginal anormal $(9,10)$.

El flujo vaginal es uno de los síntomas más frecuentes por las cuales las mujeres acuden a la atención primaria de salud y suele ser el segundo problema más común en las mujeres después de los trastornos menstruales $(9,10)$.

El acrecentamiento de estas enfermedades está en ascenso en algunos países del mundo, por factores como el comportamiento sexual, social, virginidad, facilidad de viajar, precocidad $y$ promiscuidad sexual (8).

Cuando el tracto vaginal se ve afectado por infecciones vaginales produce un cambio en la flora normal y la perdida de peróxido de hidrogeno que producen los lactobacilos (11).

La vaginitis, candidiasis y tricomoniasis constituyen el $90 \%$ de las infecciones vaginales en mujeres de edad reproductiva(12).

\section{Infecciones de transmisión sexual}

\section{Vaginosis bacteriana}

Se diagnostica microbiológicamente embarazadas y no embarazadas613. 
Gardnerella Vaginalis es el agente causal, de manera asintomática se encuentra en 30 a $40 \%$ y el $95 \%$ se encuentra en pacientes con vaginitis bacteriana (12). En gestantes y no gestantes las tasas de prevalencia van de 6 a $32 \%(13)$.

Existe una asociación entre la vaginosis bacteriana y el resultado adverso en el embarazo con un parto prematuro $(6,13)$. El grupo de personas más vulnerable a desarrollar Vaginosis son mujeres afroamericanas, mujeres de escasos recursos económicos y mujeres multíparas(13).

Gardnerella Vaginalis y bacterias anaerobias causan en la vagina un aumento en el pH y produce aminas, como la putrescina, trimetilamina produciendo un olor a pescado descompuesto(12).

Las manifestaciones clínicas que se presentan es flujo vaginal homogéneo, blanco a veces grisáceo que cubre las paredes de la vagina y de mal olor $(6,12)$.

\section{Candidiasis Vulvovaginal (CVV)}

En mujeres que acuden a los servicios de salud la colonización por Cándida es la más frecuente en infecciones de transmisión sexual (13).

Cándida Albicans es el agente causal de la candidiasis vulvovaginal, que ocasiona alteración en la flora normal de la vagina (12).

\section{Tricomoniasis vaginal}

Representa del 15-20\% (6), causada por tricomonas vaginalis, un protozoo flagelado unicelular que se contagia mediante transmisión sexual, en el hombre se encuentra de manera asintomática (13).

La infección por el protozoo tricomonas vaginalis constituye una de las infecciones de transmisión sexual más frecuentes en el mundo, en mujeres embarazadas sintomáticas se pueden desarrollar varias patologías al recién nacido como parto pretérmino, bajo peso al nacer, ruptura prematura de membrana (13).

Las manifestaciones clínicas que se presentan es flujo vaginal verde-amarillento espumoso, burbujeante, prurito asociado a Cándida (12).

\section{Sífilis}

Es una enfermedad infecciosa que se adquiere por contacto sexual y de forma congénita a través de la placenta, causada por la bacteria Treponema Pallidum (8).

\section{Virus de Papiloma Humano (VPH)}

Pertenece a la familia Papilomaviridae y contagia y se replica en el núcleo de las células epiteliales. Los VPH considerados de alto riesgo que pueden generar lesiones malignas y se asocian a casos de cáncer de cuello uterino, también se relacionan al desarrollo de neoplasias extracervicales tales como cáncer de vagina, pene, ano, cabeza y cuello(8).

El 50\% de las mujeres adolescentes y adultas jóvenes adquieren la infección VPH en los primeros 4-5 años de tener una vida sexualmente activa, el $25 \%$ desarrollan lesiones escamosas epiteliales (11).

Las infecciones vaginales que no son tratadas a tiempo pueden provocar inflamaciones a nivel pélvico, afección a las trompas de Falopio y como consecuencia causar infertilidad (14).

\section{Generalidades de los hongos}

Los hongos constituyen un grupo variado de microorganismos cuyo propósito es degradar la materia orgánica. Todos los hongos son heterótrofos que se alimentan de materia orgánica muerta, parásitos facultativos, obligados o simbiontes (15). Son organismos eucariotas y su pared está conformada por quitina (10 a 20\%), glucano (50 a 70\%) (16), manano (20\%), proteínas (3 al 10\%) y lípidos (1 a 5\%) (17), su 
membrana celular está compuesta por ergosterol (15).

En las últimas dos décadas los hongos se han convertido en una de las causas importantes de enfermedades en el ser humano, especialmente a personas que su organismo se encuentra inmunodeprimido (15).

Los hongos pueden ser unicelulares o multicelulares, basado en la morfología se divide en levaduras y mohos, morfológicamente la levadura se reproduce mediante gemación o fisión, y da como resultado que a partir de una célula progenitora (madre) produce células hijas. Las células hijas se pueden formar seudohifas (15).

Los mohos son microorganismos multicelulares forma estructuras denominadas hifas que se alargan en los extremos mediante un proceso denominado extensión apical, y pueden ser de tipo cenocíticas (muchos núcleos en el citoplasma), todas las hifas de un solo organismo puede formar un micelio (15).

En el agar y en otras superficies pueden formar colonias de mohos filamentosas, vellosas y lanosas que producen hifas vegetativas e hifas aéreas. Las hifas aéreas pueden producir estructuras conocidas como conidio (reproducción asexual), que se originan mediante gemación o por un proceso tálico, en que las hifas de fragmentan y dan lugar a los artroconidios (15).

El método para la identificación de hongos en género y especie se basa en las características y el desarrollo de los conidios, tamaño y forma. El dimorfismo es otra característica de los hongos porque pueden desarrollarse en forma de levadura y de moho (15).

\section{MATERIALES Y MÉTODOS}

$\mathrm{E}$ l presente estudio fue de tipo descriptivo, transversal; se recopiló información mediante observación directa en campo y el análisis documental para obtener información bibliográfica de tipo secundaria. Además, se aplicaron formularios elaborados para la obtener consentimiento informado para la toma de muestra y registro fotográfico evidenciándose el problema como tal en el embarazo. Se aplicó el método colorimétrico Integral System Yeast Plus y cultivos microbiológicos para identificar la especie de Cándida en mujeres embarazadas que acudieron al centro hospitalario objeto de estudio.

Se solicitó autorización mediante un oficio a la autoridad del Hospital, para el desarrollo del análisis de las muestras en el área de Microbiología en los meses febreroabril 2019, al mismo tiempo se tuvo acceso al Registro Automatizado de Consultas y Atenciones Ambulatorias (RDACCA y sistema PRAS).

La población estuvo conformado por 506 mujeres embarazadas del tercer trimestre de gestación que se atienden en la consulta externa mensualmente en el Hospital. La muestra estuvo conformada por 100 mujeres embarazadas entre 19 a 30 años de edad que presentaban secreción vaginal y con diagnóstico de Candidiasis las cuales aceptaron ser parte del estudio y firmaron el consentimiento informado. 
Calculo para la obtención de la muestra con los siguientes parámetros:

- $\mathrm{Za}^{2}=$ nivel de confianza de $95 \%$

- $\mathrm{P}=$ proporción de la variable a la derecha $0.03 \%$

- $\mathrm{Q}=$ proporción de la variable a la izquierda $0.97 \%$

- $\mathrm{E}^{2}=$ nivel de precisión de 0.03

- $\mathrm{N}=$ universo conformado por 506 mujeres

$$
\begin{aligned}
& \mathrm{n}=\frac{\mathrm{N} \cdot \mathrm{Za}^{2}\left(\mathrm{P}^{*} \mathrm{Q}\right)}{\mathrm{E}^{2}(\mathrm{~N}-1)+\mathrm{Za}^{2}\left(\mathrm{P}^{*} \mathrm{Q}\right)} \\
& \mathrm{n}=\frac{506(1.962)^{2}(0.03 \times 0.97)}{(0.03)^{2}(506-1)+(1.962)^{2}(0.03 \times 0.97)} \\
& \mathrm{n}=\frac{506(0.1118)}{0.0009(505)+3.8416(0.02910)} \\
& \mathrm{n}=\frac{56.571}{0.566} \\
& \mathbf{n}=\mathbf{1 0 0} \mathbf{R} /
\end{aligned}
$$

\section{Criterios inclusión}

- Pacientes gestantes que acuden por consulta externa en el tercer trimestre de gestación al Hospital Obstétrico Ángela Loayza de Ollague.

- Pacientes embarazadas de 19 a 30 años con sintomatología asociadas a candidiasis atendidas durante el periodo del tiempo establecido en la investigación.

- Pacientes que autorizaron ser parte del estudio y firmaron el consentimiento informado.

- Pacientes en el tercer trimestre de gestación.

\section{Criterios de exclusión}

- Pacientes gestantes que no acuden al Hospital Obstétrico Ángela Loayza de Ollague.

- Antecedentes de alguna aplicación tópica, cremas, óvulos vaginales

- Toma de medicamentos previo a la toma de muestra.

- Mujeres no embarazadas.

- Mujeres embarazadas que no autorizaron ser parte del estudio. 
Métodos de laboratorio

\section{Métodos cualitativos utilizados}

Método cualitativo

Método de tinción simple

Método de tinción doble

Método colorimétrico

Método basado en medios de cultivo
Examen microscópico en fresco con suero

fisiológico, hidróxido de potasio.

Tinción de azul de lactofenol.

Tinción de Gram.

Integral System Yeast Plus.

Agar Saboraud para el crecimiento de levaduras.

Método de tubo Germinal

Métodos cuantitativos

\begin{tabular}{ll}
\hline Método colorimétrico & Métodos cuantitativos \\
& $\begin{array}{l}\text { Medición de } \mathrm{pH} \text { a la muestra de secreción } \\
\text { vaginal. }\end{array}$ \\
\hline
\end{tabular}

\section{Técnicas de laboratorio}

\section{Análisis químico}

Técnica: medición de pH Se comparó la variación de pH con una escala de color, se interpreta si la muestra posee $\mathrm{pH}$ ácido, neutro o alcalino.

\section{Técnica: examen en fresco}

Técnica: tinción de Gram

Técnica de azul de

Lactofenol

Técnica de hidróxido de potasio $\mathrm{KOH} 10 \%$

Técnica : tubo Germinal

Técnica: Agar Saboraud

Técnica: Integral System Yeast Plus

\section{Análisis Microscópico}

Se pudo observar microscópicamente estructuras como bacterias, células y levaduras presentes en muestras.

Permitió identificar bacterias Gram Positivas y Gram Negativas por su coloración rosa o morado (15).

Permite visualizar estructuras de hongos que son teñidas de azul y aumentar el contraste (15).

Permite observar elementos fúngicos que están presentes en los tejidos (15).

\section{Análisis Macroscópico}

Prueba específica para diferenciar Cándida Albicans de otras especies de Cándida spp.

Medio selectivo que se utiliza para aislar hongos de importancia clínica (15).

Sistema de 24 pozos que contiene sustrato bioquímico y antimicóticos, para la identificación de levaduras de importancia clínica $(6,1)$. 


\section{Procedimiento para la toma de muestra}

Previo a la toma de muestra se colocó el equipo de bioseguridad: mandil, guantes, bata de laboratorio, cofia, cubreboca y cumpliendo con el protocolo de laboratorio.

Se verificó si el paciente cumple con las indicaciones previas a la toma de muestra.

Se le solicitó a la paciente que se coloque una bata para la toma de muestra, y se recueste en una camilla en posición ginecológica.

Seguidamente, ya la paciente ubicada en posición ginecológica se procedió a la colocación del espéculo sin lubricante. (Figura 1).

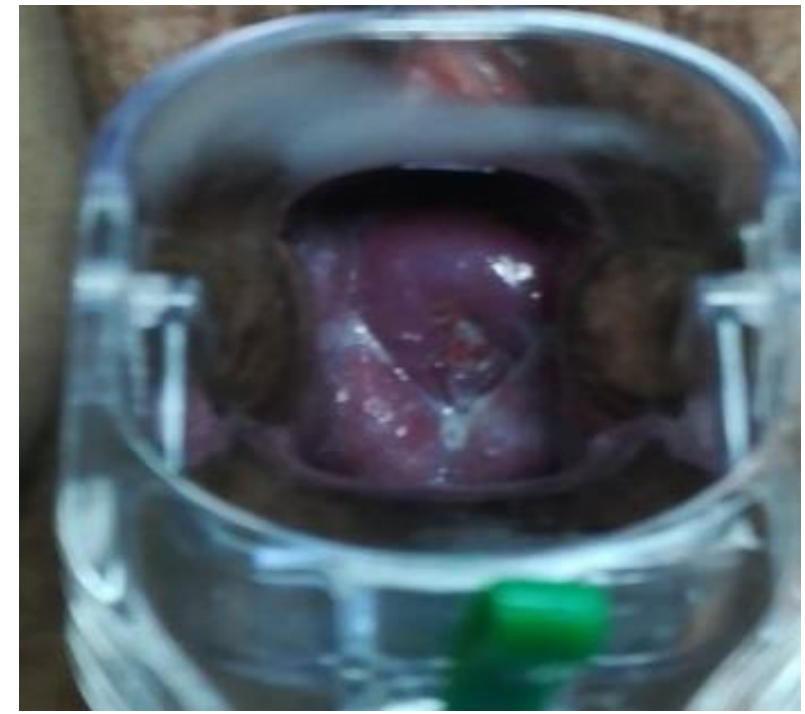

Figura 1. Introducción del espéculo vaginal, observándose el cuello uterino de la mujer

Se tomó 3 hisopos que se rotaron en la pared del canal de la vagina, se retiró cuidadosamente evitando contaminación.

El primer hisopo se lo utilizó para la determinación de pH y luego se lo colocó en un tubo donde había suero fisiológico (de acuerdo a la técnica detallada en métodos). (Figura 2).

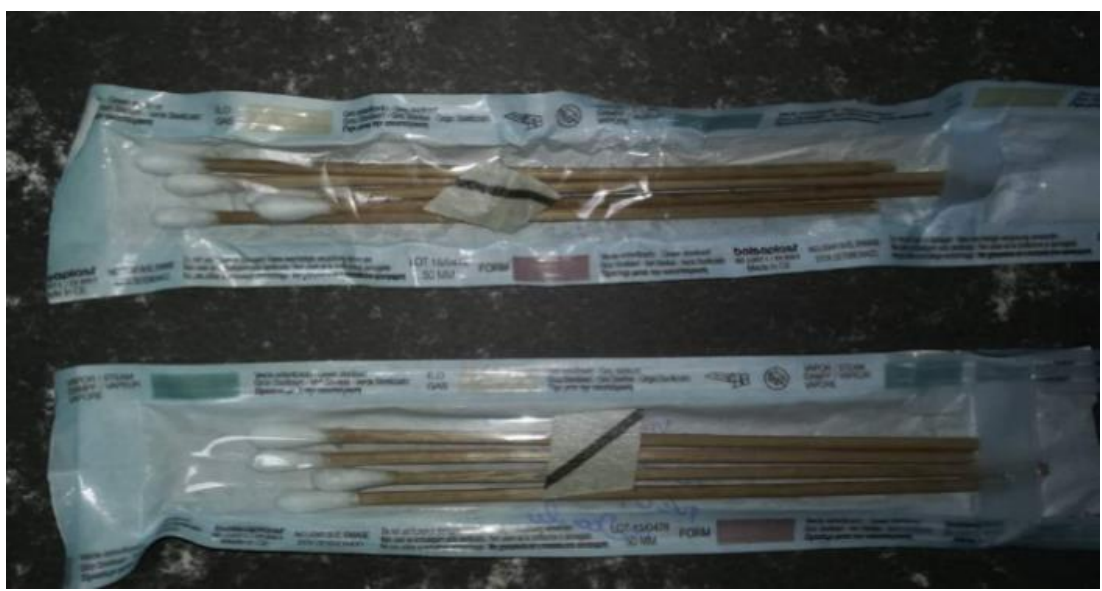

Figura 2. Hisopos estériles para la toma de muestra 
El segundo hisopo se colocó en un portaobjeto que se utilizó para tinción de Gram y azul de lactofenol (de acuerdo a la técnica detallada en métodos).

Una vez tomada la muestra a todas las mujeres en los horarios de 8:00-10:00am se procede a la observación al microscopio con lente de 40x para el examen en fresco y azul de lactofenol, para tinción de Gram se colocó una gota de aceite de inmersión y se observó con lente de 100x. (Figura 3).

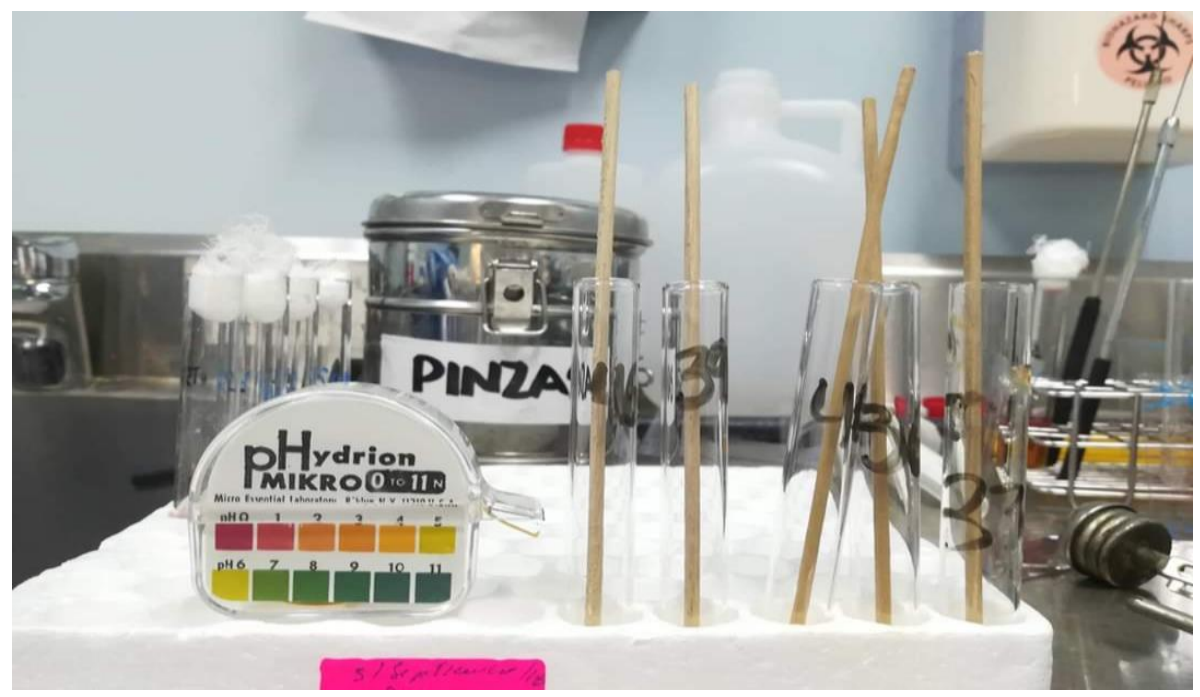

Figura 3. Determinación de pH, y tubos de ensayo para la observación de examen en fresco

Y el tercer hisopo realizando un estriado se lo colocó en una caja Petri rotulada, previamente elaborado el medio de cultivo Saboraud, medio selectivo para hongos y levaduras. (Figura 4 y 5 ).

Figura 4. Observación al microscopio de las muestras de secreción vaginal

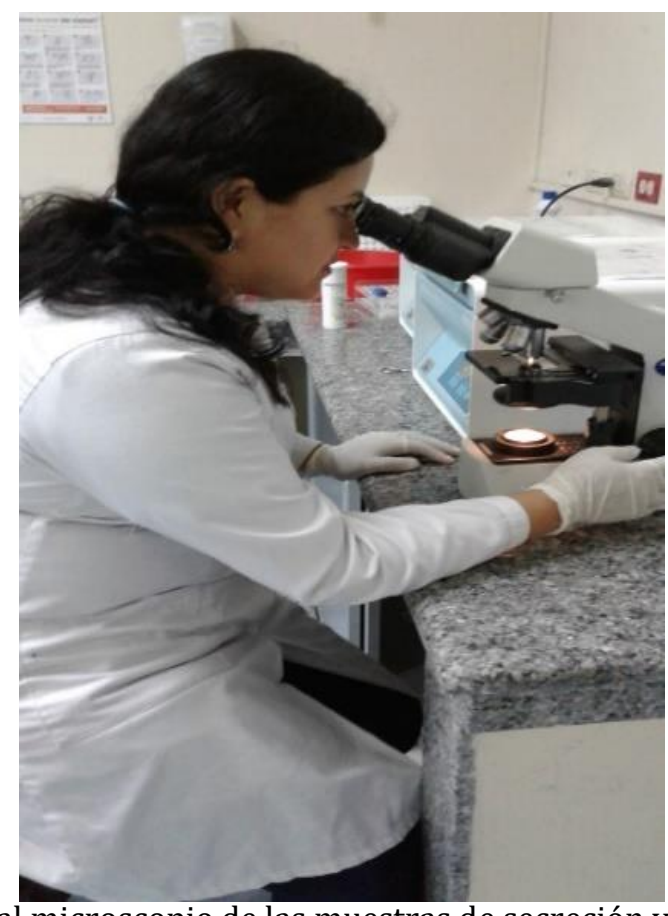




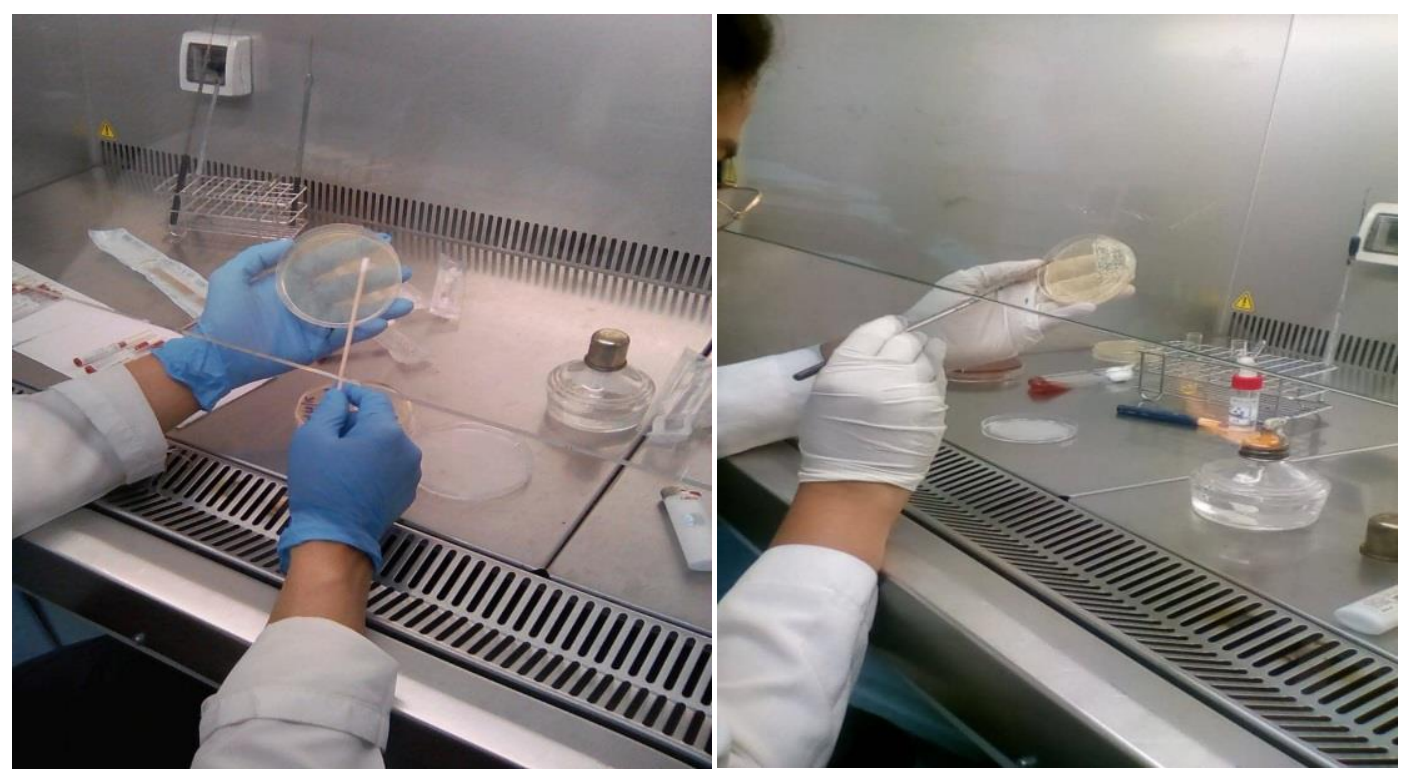

Figura 5. Estriado en caja Petri con el medio de cultivo Saboraud

Posteriormente lo lleva a la incubadora a una temperatura de $35.4^{\circ} \mathrm{C}$ a $24-48$ horas.

Luego de las 24-48 horas se pueden observar colonias de levaduras que por su color y aspecto se diferencian unas de otras. (Figura 6 y 7 ).

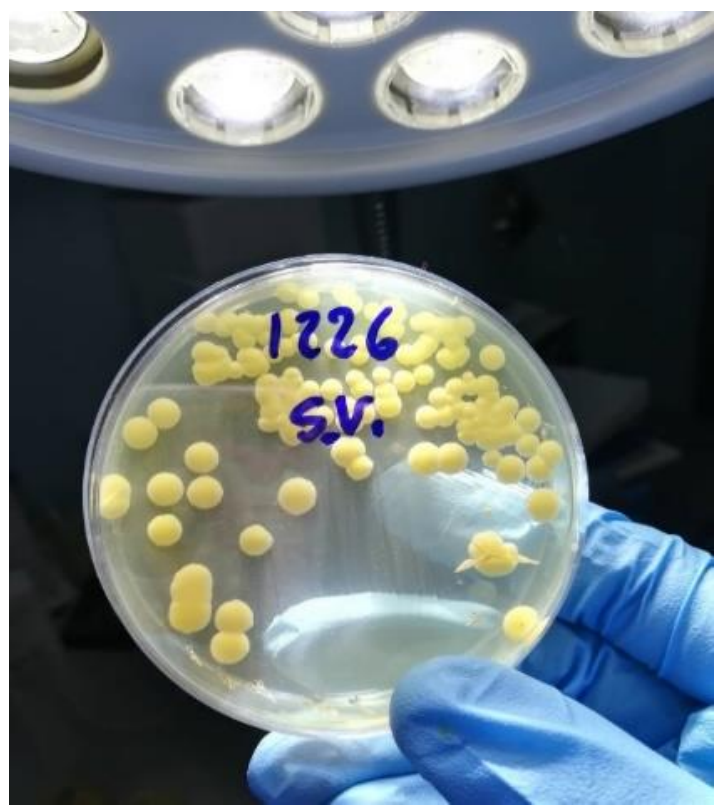

Figura 6. Caja Petri con medio Saboraud rotulada con el código único para cada paciente 


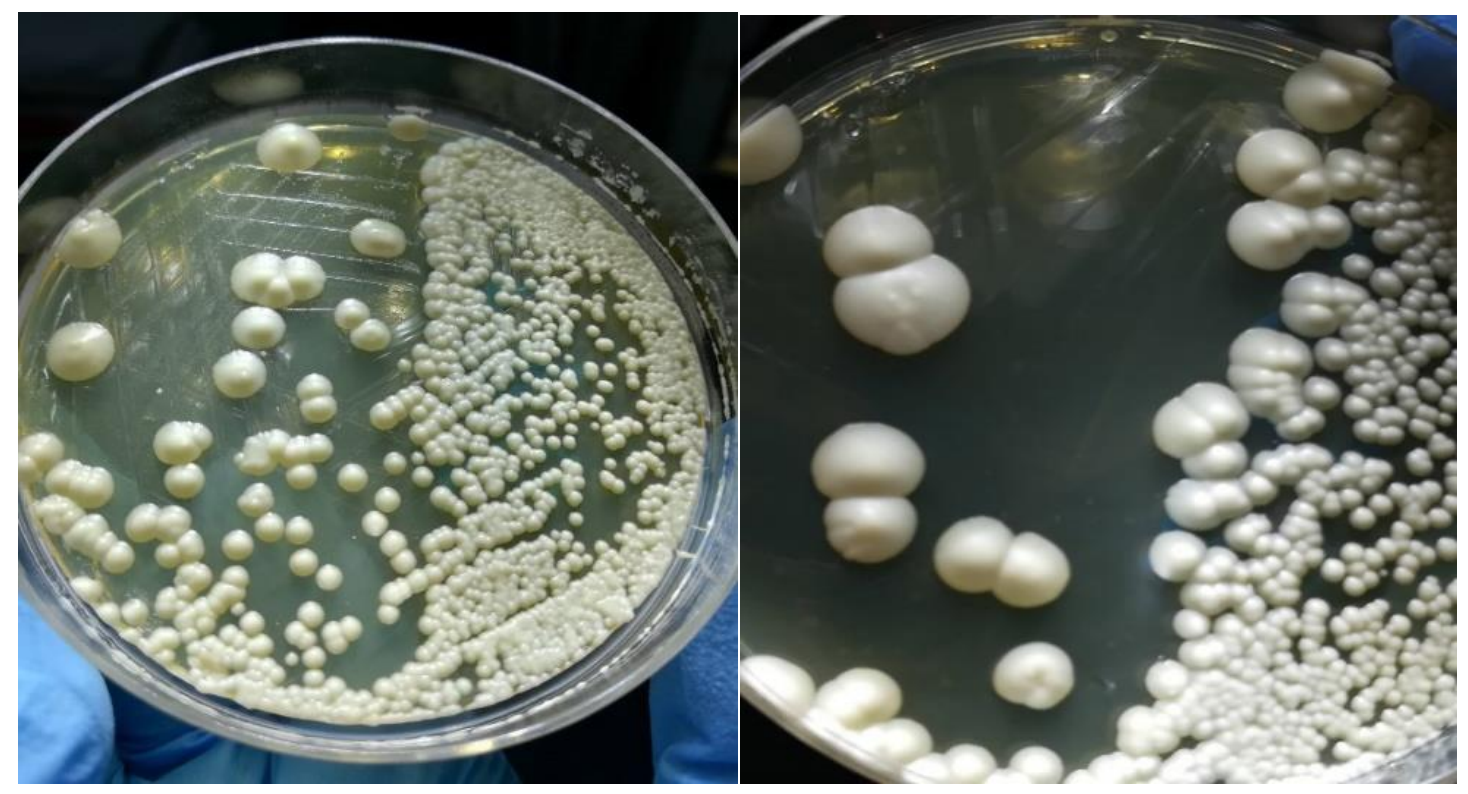

Figura 7. Colonias de Cándida Albicans

Para la realización del tubo germinal se toma una colonia del medio Saboraud con suero de un paciente se lleva a incubación a $37^{\circ} \mathrm{C}$ y se observa al microscopio con lente de 40x (de acuerdo a la técnica detallada de métodos). (Figura 8).

Para la utilización del kit Integral System Yeast Plus se toma una colonia del medio Saboraud y se lo lleva a la incubadora a $\mathrm{T} 35.4^{\circ} \mathrm{C}$. (Figura 9).

Luego de 48 horas se identifica especies de Cándidas en muestras de secreción vaginal y la sensibilidad ante los antimicóticos.

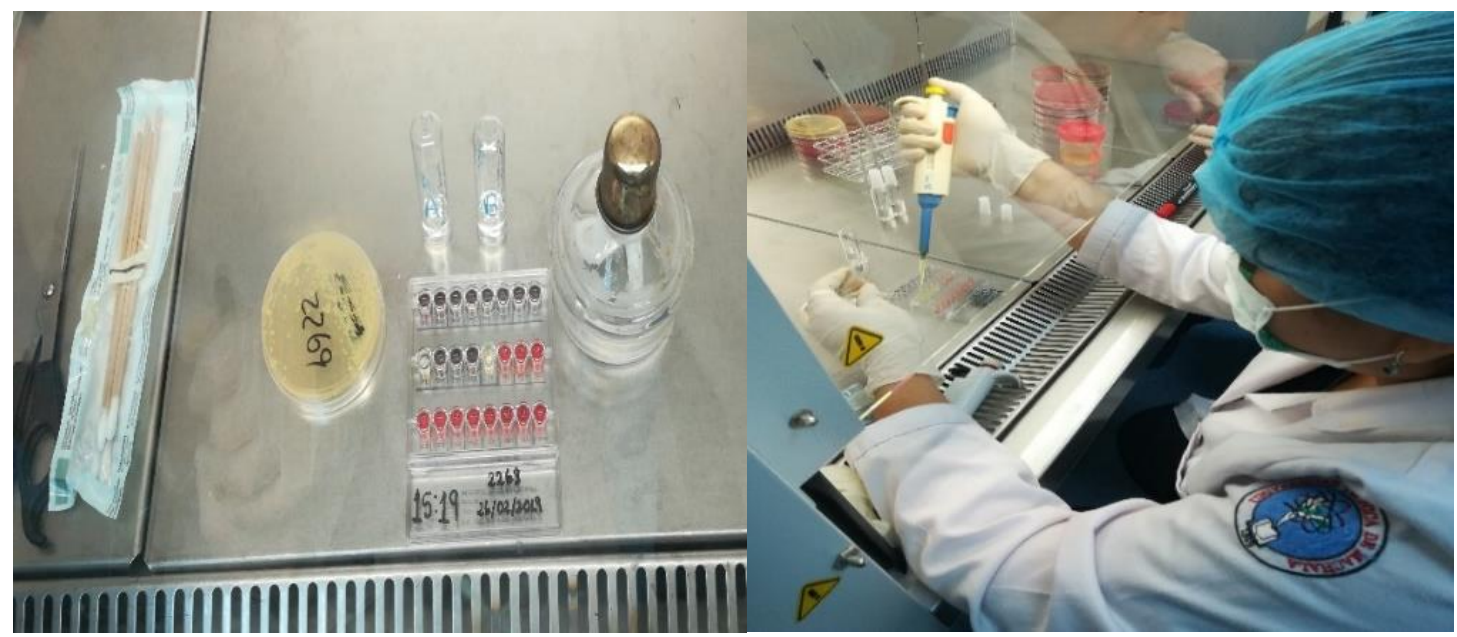

Figura 8. Inoculación de levaduras en el kit Integral System Yeast Plus 

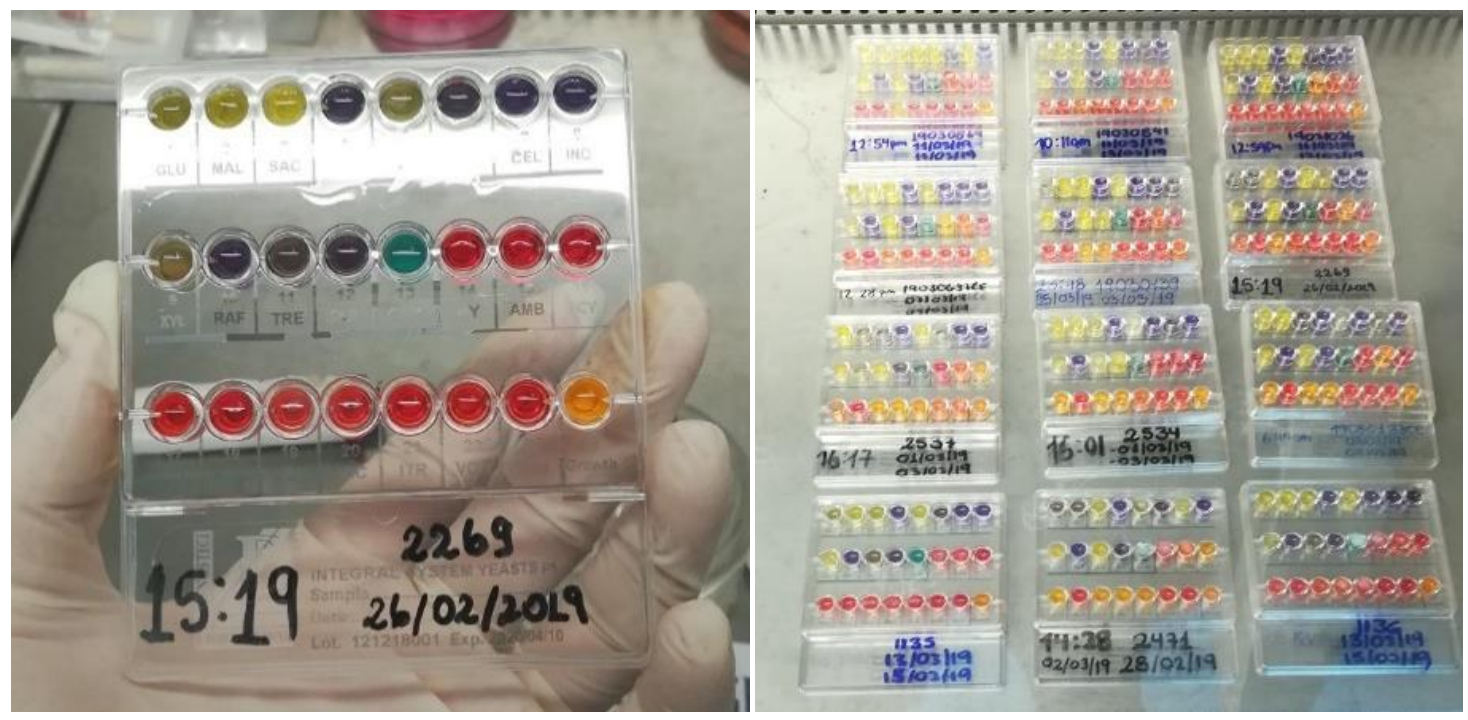

Figura 9. Lectura después de 48 horas del kit

\section{RESULTADOS}

$\mathrm{L}$ as especies asociadas a Candidiasis vulvovaginal aisladas de las 100 mujeres embarazadas que acudieron al Hospital mostraron que Cándida Albicans es la especie mayor aislada en muestras de secreciones vaginales, la segunda especie perteneciente a las No-Albicans aislada en el estudio fue Cándida Glabrata, y aislamientos menos predominantes fueron Cándida Krusei, Tropicalis y Cándida Parapsilosis. (Gráfico 1).

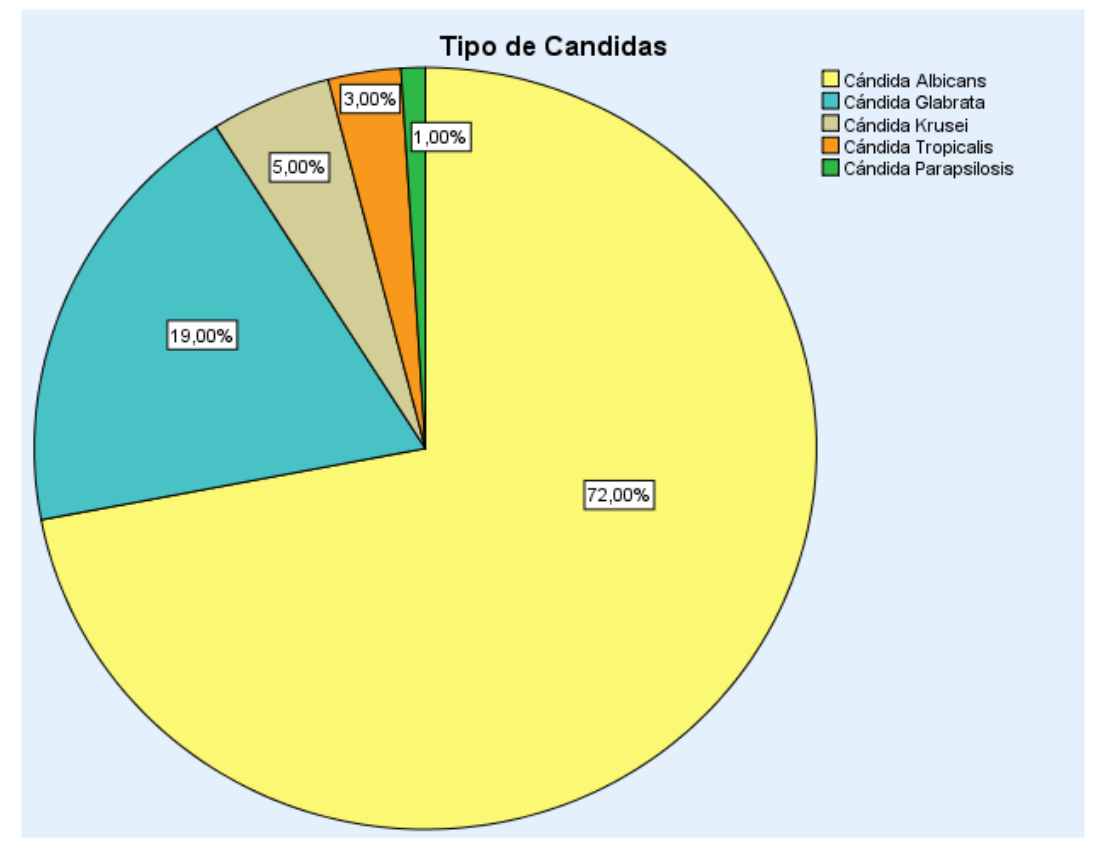

Gráfico 1. Identificación de especies de Cándidas en secreciones vaginales de mujeres embarazadas. 
La distribución de las especies de Cándida según los grupos de edad de las mujeres embarazadas que asistieron al Hospital mostró que la distribución mayor fue en el grupo de edad de 23-26 años (59\%), seguido del grupo de 19-22 años (28\%) y de 27-30 años (13\%). (Gráfico 2).

La distribución en los rangos de edad puede deberse a que son jóvenes sexualmente activas, de las cuales algunas exceden el uso de antibióticos o usan anticonceptivos de las cuales son factores de riesgo para una infección por Cándida. Y por su estado de gestación sufren cambios hormonales en su cuerpo, y produce una alteración en la flora vaginal.

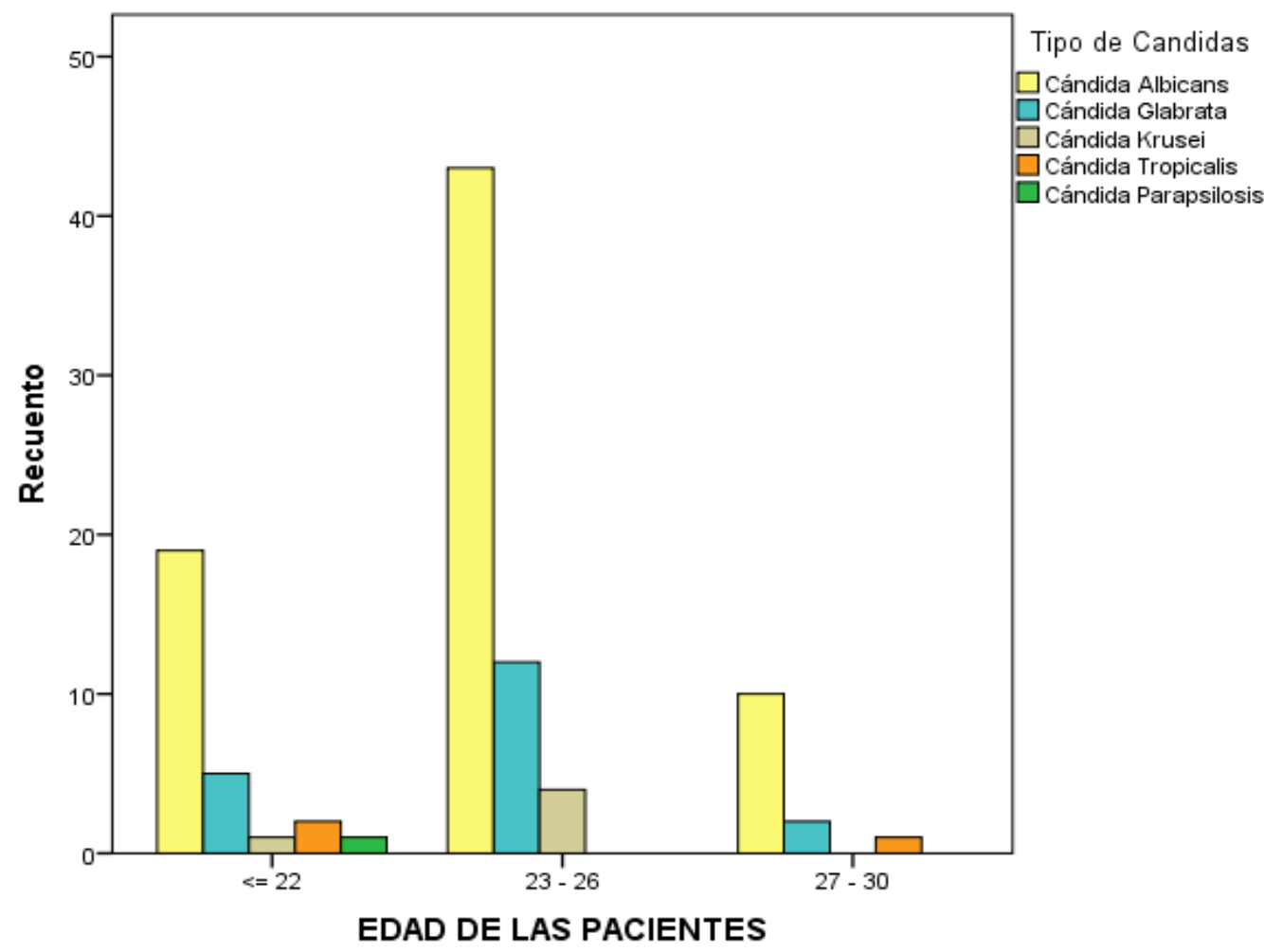

Gráfico 2. Edad de las mujeres embarazadas en relación de las especies de Cándidas encontradas en el estudio

De los 72 casos encontrados de Cándida Albicans revela que son susceptibles a la anfotericina B $(2 \mathrm{ug} / \mathrm{ml})$, Flucitosina $(16 \mathrm{ug} / \mathrm{ml})$, Econazol $(2 \mathrm{ug} / \mathrm{ml})$, Ketoconazol (0.5ug/ml), Clotrimazol (1ug/ml), Miconazol (1ug/ml), Itraconazol $(1 \mathrm{ug} / \mathrm{ml})$, Voriconazol $(2 \mathrm{ug} / \mathrm{ml})$ y Fluconazol $(4 \mathrm{mg} / \mathrm{L})$, mientras que para la Nistatina $(1.25 \mathrm{ug} / \mathrm{ml})$ fue sensible. (Grafico 3). 


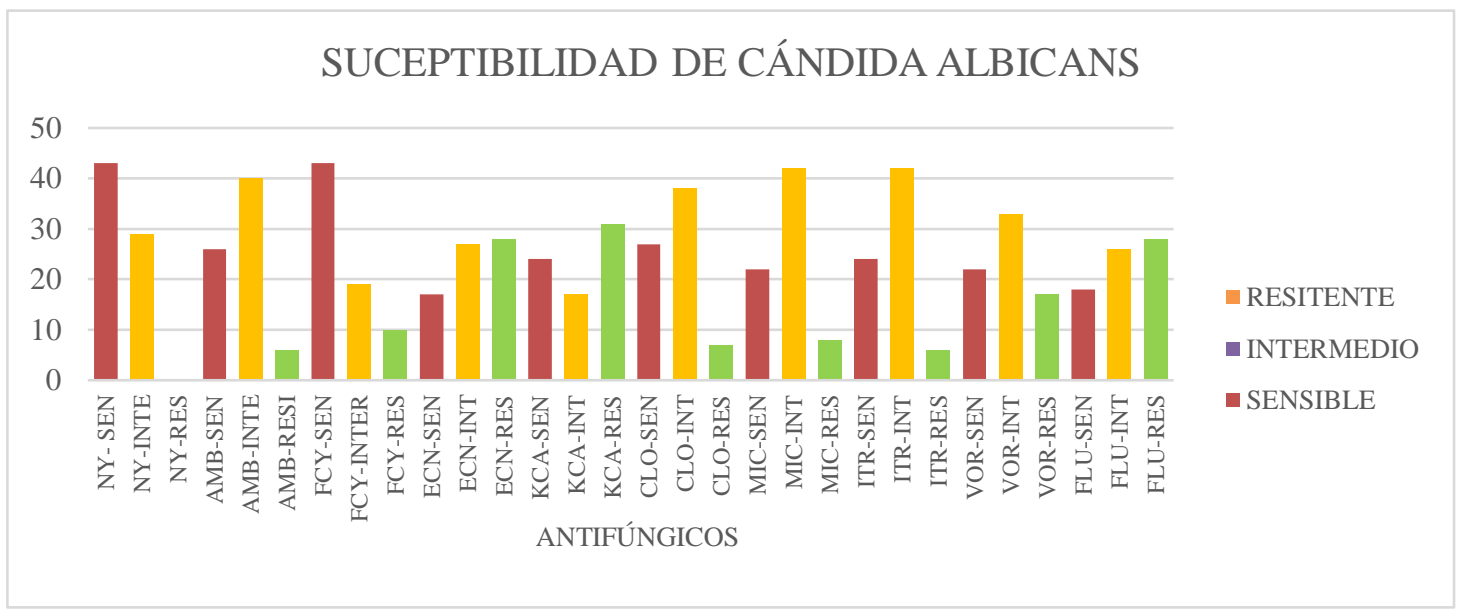

Gráfico 3. Susceptibilidad de Cándida Albicans ante los Antifúngicos

De los 19 casos encontrados de Cándida Glabrata revela que son sensibles a la Nistatina (1.25ug/ml), Anfotericina B (2ug/ml) y son susceptibles al Econazol $(2 \mathrm{ug} / \mathrm{ml})$, Ketoconazol (0.5ug/ml), Miconazol (1ug/ml), Itraconazol (1ug/ml), Voriconazol $(2 \mathrm{ug} / \mathrm{ml})$, mientras que la resistencia más alta de Cándida Glabrata fue para Clotrimazol $(1 \mathrm{ug} / \mathrm{ml})$, Flucitosina (16ug/ml) y Fluconazol (4mg/L). (Gráfico 4).

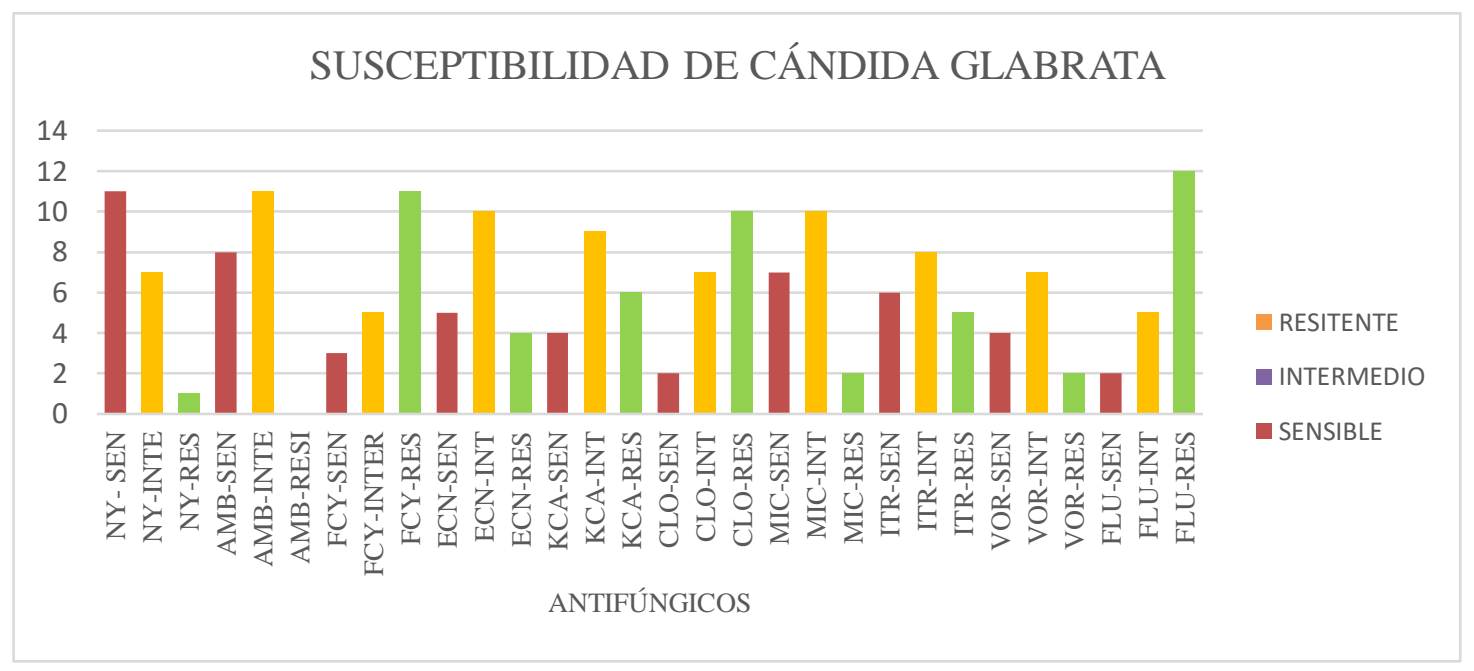

Gráfico 4. Susceptibilidad de Cándida Glabrata ante los Antifúngicos

De los 5 casos encontrados de Cándida Krusei revela que son sensibles a la Anfotericina B (2ug/ml), Clotrimazol (1ug/ml), Miconazol $(1 \mathrm{ug} / \mathrm{ml})$, y son susceptibles a la Nistatina $(1.25 \mathrm{ug} / \mathrm{ml})$, Voriconazol $(2 \mathrm{ug} / \mathrm{ml})$. Mientras que presentó resistencia alta a la Flucitosina (16ug/ml), Ketoconazol $(0.5 \mathrm{ug} / \mathrm{ml})$, Itraconazol $(1 \mathrm{ug} / \mathrm{ml})$ y Fluconazol (4mg/L). (Gráfico 5). 


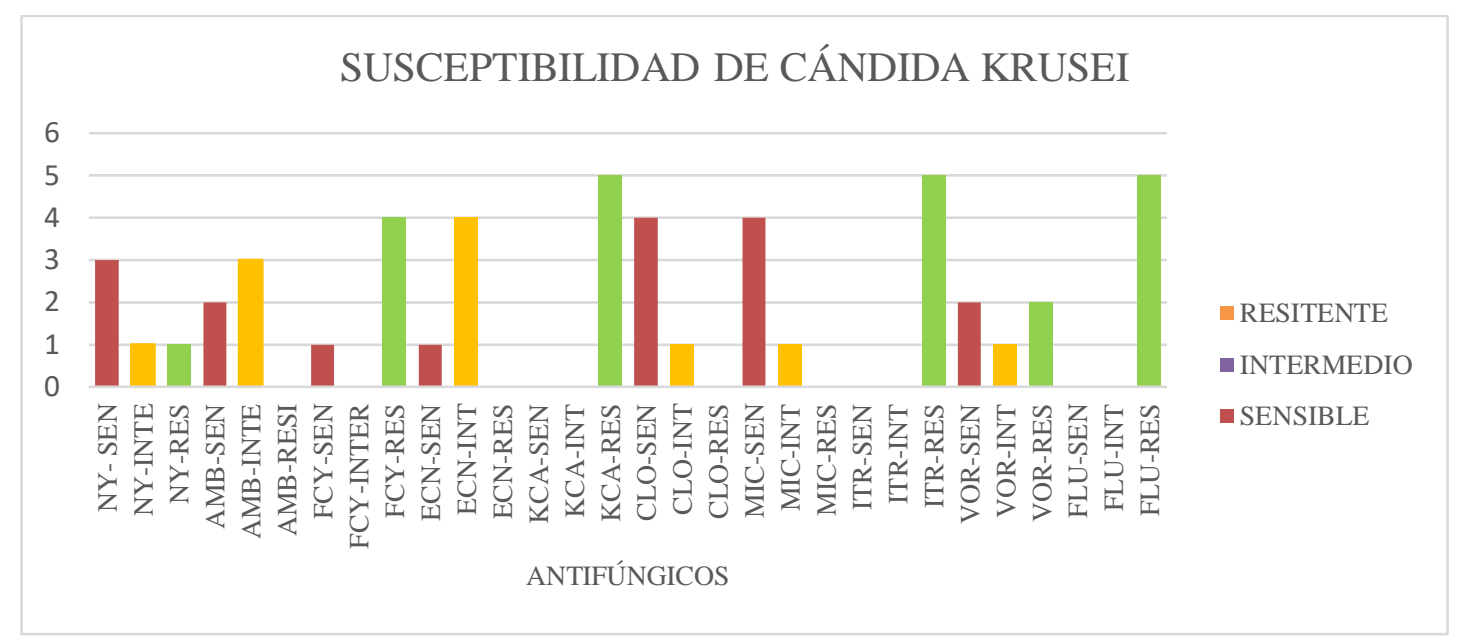

Gráfico 5. Susceptibilidad de Cándida Krusei ante los Antifúngicos

De los 3 casos encontrados de Cándida Tropicalis revela susceptibilidad de Nistatina $(1.25 \mathrm{ug} / \mathrm{ml})$, Flucitosina $(16 \mathrm{ug} / \mathrm{ml})$, Ketoconazol $(0.5 \mathrm{ug} / \mathrm{ml})$, Clotrimazol $(1 \mathrm{ug} / \mathrm{ml})$, Miconazol (1ug/ml), Itraconazol $(1 \mathrm{ug} / \mathrm{ml})$, es resistente a la Anfotericina B $(2 \mathrm{ug} / \mathrm{ml})$, Econazol (2ug/ml), y Fluconazol (4mg/L) (Gráfico 6).

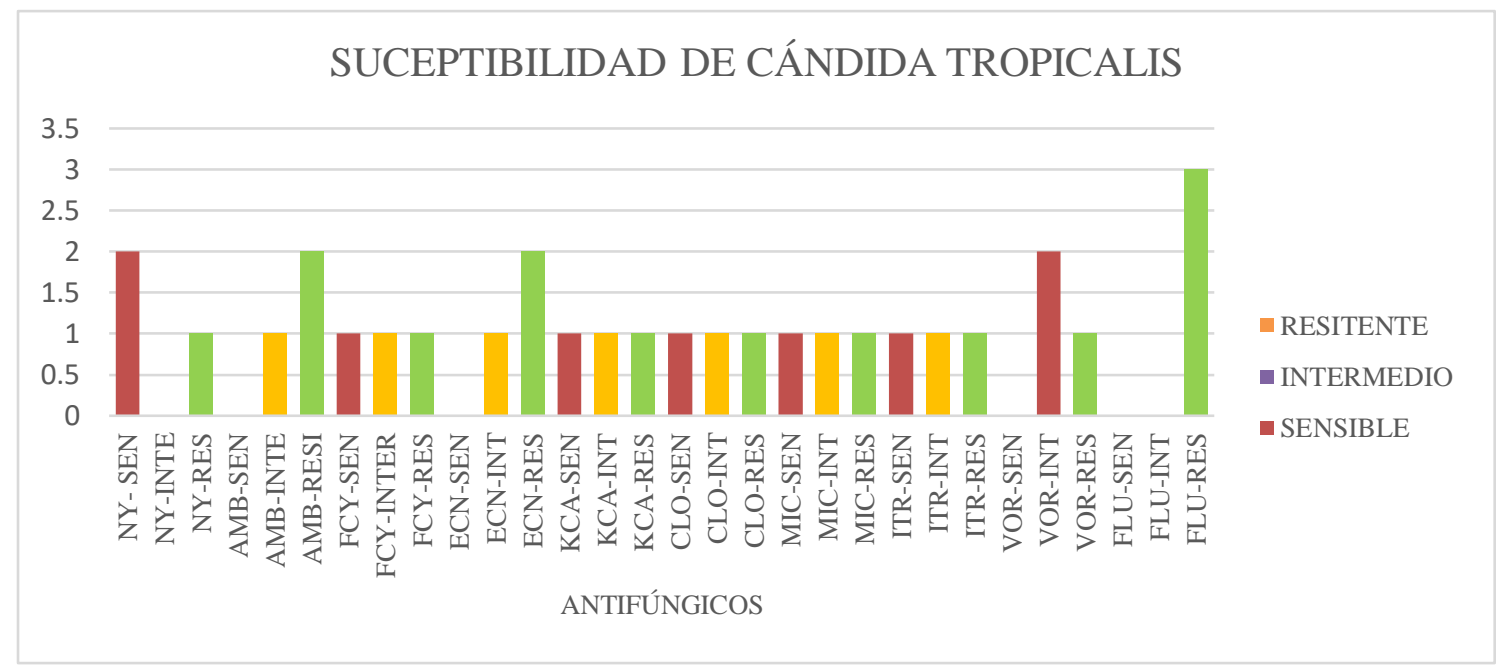

Gráfico 6. Susceptibilidad de CándiTropicalis ante los Antifúngicos

De 1 caso encontrado de Cándida Parapsilosis revela sensibilidad en la Nistatina (1.25ug/ml), Econazol (2ug/ml), Clotrimazol (1ug/ml), Miconazol (1ug/ml), Itraconazol (1ug/ml), presenta sensibilidad intermedia en los antifúngicos Flucitosina (16ug/ml), ketoconazol $(0.5 \mathrm{ug} / \mathrm{ml})$ y resistencia en Anfotericina B $(2 \mathrm{ug} / \mathrm{ml})$, Voriconazol $(2 \mathrm{ug} / \mathrm{ml})$ y Fluconazol (4ml/L) (Gráfico 7). 


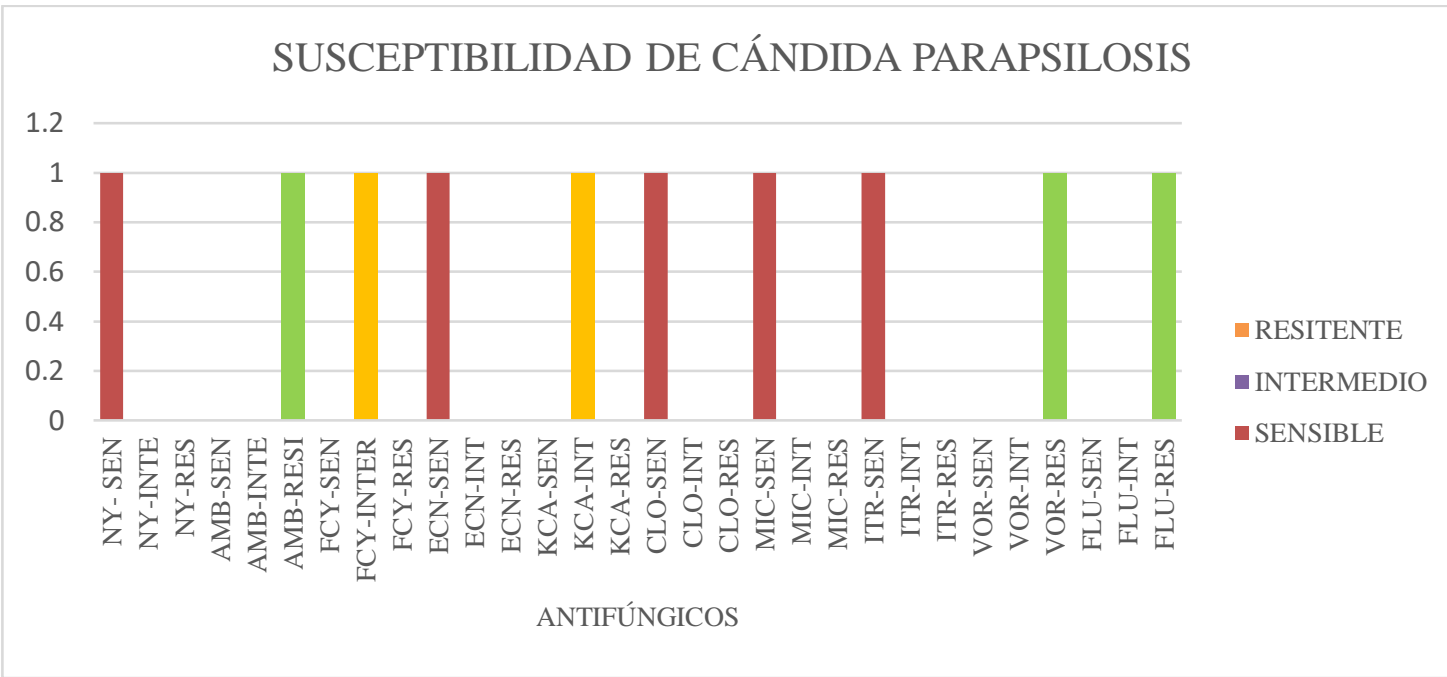

Gráfico 7. Susceptibilidad de Cándida Parapsilosis ante los Antifúngicos

\section{Discusión}

Cándida Albicans forma parte de la flora autóctona de nuestro del cuerpo y no producirá infección al menos que haya alterado la respuesta de defensa en el huésped comportándose de manera oportunista y causando infección (18). En la vagina la especie Cándida Albicans causa candidiasis vulvovaginal que es muy común en mujeres embarazadas, presentando recurrencia de esta infección (19).

En este estudio la prevalencia de la infección por Cándida fue del (44.98\%), en comparación del estudio de prevalencia que se realizó en la India demuestra una prevalencia de $37.3 \%$ (19). En el estudio de prevalencia en el sur de Libia coincide con nuestro estudio, revela una prevalencia de $43.8 \%$ en mujeres embarazadas (14), otro estudio que se realizó en Túnez demuestra una prevalencia del $32.87 \%$ (20), otro estudio que se realizó en Nigeria Ogbomoso la prevalencia fue muy baja del $25 \%$ (21). Un estudio realizado en Etiopía revela que la prevalencia de ese estudio fue de $41.4 \%$ (22). Otro estudio concuerda con la de prevalencia que se realizó en la India, fue de $35 \%$ (10). Un estudio realizado en Benin City demuestra que la prevalencia fue del $58.0 \%$
(23), lo que se encontró elevada a la prevalencia de este estudio.

Hay estudios que demuestran que mujeres en el tercer trimestre de gestación son más vulnerables a desarrollar candidiasis, en nuestro estudio se seleccionaron solo pacientes del tercer trimestre de gestación, Un estudio realizado en Nigeria revela que en el tercer trimestre es más alta la prevalencia de candidiasis representando un $63.3 \%$ (24), el $10 \%$ en el primer trimestre, $26.7 \%$ en el segundo trimestre (24). Otro estudio demuestra que en el primer trimestre eran más vulnerables a desarrollar episodios de candidiasis con un $49 \%$, el segundo trimestre con una 33\% y en el tercer trimestre un 18\% (3). Un estudio que se realizó en Medellín Colombia indica que el mayor aumento de infecciones por Cándida fue en el tercer trimestre 50.7\% y en el primer trimestre 14.9\% (2). En un estudio que se realizó Nigeria Ogbomoso se observó una mayor prevalencia de $54.3 \%$ en el segundo trimestre de gestación, en el primer trimestre $25.7 \%$ y en el tercer trimestre $20 \%$ (21). Otro estudio coincide con el estudio realizado en Nigeria, en el segundo trimestre representó 58.5\%, seguido del primer trimestre $53.2 \%$ y en el 
tercer trimestre $50.7 \%$, pero los valores del primer trimestre con los del tercer trimestre se duplicaron en comparación del estudio realizado (25), otro estudio coincide que en el segundo trimestre de gestación existe una mayor prevalencia $55 \%$ y en el primer trimestre $34.11 \%(10)$. En el centro de Asaba Nigeria no está de acuerdo con el estudio mencionado y concuerda que en el Tercer trimestre de gestación existe una mayor prevalencia de Candidiasis en mujeres embarazadas $47 \%$ (9), al igual que el estudio que se realizó en Benin City concuerda que el tercer trimestre poseen el mayor riesgo en contraer candidiasis vulvovaginal (23).

Lo que permite poner en discusión esta información relacionada con los trimestres de gestación, Las mujeres embarazadas en el primer y segundo trimestre de embarazo por su estado sufren un estrés emocional y su sistema inmunológico se descompensa (24). Pero en el tercer trimestre de gestación atribuyen a un mayor estrés emocional a la espera de su hijo, lo que hace que el nivel de mecanismo de la vagina disminuya provocando infecciones por Cándida (24).

En este estudio la distribución de especies de Cándidas es más alta en edades de 23 a 26 años 59\%, seguido de 19 a 22 años $28 \%$ y 27 a 30 años $13 \%$. En un estudio realizado en Nigeria describe que las mujeres embarazadas de 26 a 30 años poseen una distribución alta de especies de Cándidas 63\%30, seguido de las edades 31 a 35 años $16.7 \%$ y 20 a 25 años representando el $10 \%$. Cándida Albicans fue la especie que se aisló todos los grupos de edad, Cándida tropicalis y Krusei se aisló en grupo de edad de 26 a 30 años y Cándida Glabrata en grupo de 20 a 25 años y 26 a 30 años (24). Un estudio concuerda con lo mencionado en el estudio realizado en Nigeria candidiasis vaginal era más predominante en grupo de edad de 26 -35 años 48.98\%, seguido del rango de edad de 16 a 25 años $28.57 \%$ y de
36-45 años (26). En un estudio realizado en el sur de Libia indica que los grupos de edad de 16 a 25 años 44.4\%, poseen una prevalencia alta de infección por Cándida, seguido por grupos de edad de 26 a 35 años $34.9 \%$, y 36 a 45 años 20.6\%14. En un estudio realizado en Túnez demuestra que en edades de 25 a 34 años de edad se ve afectado por la candidiasis36. En Benin City concuerda con el estudio realizado en Túnez, obtuvieron mayor prevalencia el rango de edad de 28 a 32 años en mujeres embarazadas (23). En Ogbosomo Nigeria en el rango de edad donde se determinó mayor candidiasis en mujeres embarazadas fue 2029 años, seguido de 30 a 39 años (21). En el centro de Asaba Nigeria en las edades de 2029 tuvieron una mayor prevalencia de candidiasis vaginal $38.5 \%$ similares al estudio en Ogbosomo Nigeria (9). Otro estudio indica que el grupo de edad donde se encontró mayor prevalencia de candidiasis fue en edades de $21-25$ años $40.44 \%$ seguido de 26 a 30 años representando 32.48\% coincidiendo con este estudio (10).

A través de este estudio, se demostró que los aislamientos de Cándida Albicans en mujeres embarazadas representaron el 72\% y de las especies No Albicans fue del 28\%, 19\% para Cándida Glabrata, 5\% para Cándida Krusei, 3\% para Cándida Tropicalis y 1\% para Cándida Parapsilosis. En un estudio que se realizó en la India en mujeres embarazadas, el $60 \%$ de los casos eran de Cándida Albicans y el 40\% de no Albicans (19). En otro estudio en Egipto el porcentaje de Cándida Albicans fue del 86.5\%, Cándida Glabrata 10.8\%, Cándida Tropicalis 2.5\% y Cándida Krusei 0\% (18). Otro estudio que se realizó en Colombia el $58.9 \%$ de los aislamientos fueron para Cándida Albicans, seguido por Cándida Tropicalis 8.9\%, Cándida Krusei 5.4\%, Cándida Parapsilosis $5.4 \%$ (27). En Nigeria las especies aisladas de Cándidas en mujeres embarazadas fueron 
Cándida Albicans 66.7\%, Cándida Glabrata 23.3\%, Cándida Tropicalis 6.7\% y Cándida Krusei $3.3 \%$ (24), coincidiendo con este estudio la especie más común aislada Cándida Albicans.

En un estudio que se realizó en el sur de Libia revelan que Cándida Albicans fue la especie más dominante representando un 92\% (14). En Túnez concuerdan con el estudio realizado Cándida Albicans fue la especie que se aisló con mayor frecuencia $76.61 \%$, seguido de Cándida Glabrata 17.18\% (20). En otro estudio se aislaron 758 especies de Cándidas de las cuales Cándida Albicans obtuvo un mayor porcentaje 82.6\%, seguido de Cándida Glabrata 10.2\%, Cándida Krusei 2.5\%, Cándida Parapsilosis 2.4\% y Cándida Tropicalis $1.8 \%$ (7). Estudios indican que el porcentaje de Cándida Albicans es del $80-90 \%$ y de especies No albicans el 20\% (7). Cándida Glabrata se aisla en un $10 \%$, y Cándida Tropicalis de un 1 al 5\% (7). En etiopia un estudio realizado reveló que Cándida Albicans es la especie que se aisló en mayor porcentaje representando un $58.6 \%$ y de las especies No-Albicans $41.4 \% \quad$ (22). En Irak los aislamientos de Cándida Albicans representaron 43.4\%, y demuestra que la segunda especie aislada en mujeres embarazadas es Cándida Krusei 28.3\% (28). Otro estudio muestra que los 85 aislamientos de Cándida Albicans fue de $64.04 \%$ y la segunda especie encontrada fue Cándida Glabrata 12.35\%, Cándida Dublenesis 10.11\%, Cándida Tropicalis 5.61\% y Cándida Krusei 3.37\% (10).

En los estudios mencionados se muestran variaciones sobre las especies aisladas, ya que la distribución geográfica de las especie de Cándida varían, y a un más las especies No-Albicans, debido al abuso de antifúngicos las especies llegan a ser resistentes, pero Cándida Albicans sigue siendo una de las especies que en su mayoría se aísla en secreciones de mujeres embarazadas como no embarazadas.

En este estudio la Cándida Albicans fue susceptible a la Anfotercina B, Flucitosina, Econazol, Ketoconazol, Clotrimazol, Miconazol, Itraconazol, Voriconazol, Fluconazol, y sensible a la Nistatina. Un estudio realizado sobre la susceptibilidad revela que Cándida Albicans fue susceptibles al Fluconazol, Ketoconazol, Itraconazol y Nistatina (29). Otro estudio informa que Cándida Albicans es susceptible al Clotrimazol (29), mientras que se detectó resistencia al Fluconazol, Ketoconazol y Econazol (29). Otro estudio de susceptibilidad realizado en Monagas demuestra que Cándida Albicans es 100\% sensible al fluconazol, pero hay información que la resistencia de la especie Albicans al fluconazol es del 15\% (1).

La susceptibilidad de Cándida Glabrata fue resistente al Clotrimazol, Flucitosina y Fluconazol, coincide con otro estudio de susceptibilidad que demuestra que Cándida Glabrata fue resistente al Ketoconazol, Clotrimazol y Fluconazol (29). 1 de cada 6 aislamientos de Cándida Glabrata mostraron resistencia a los azoles (29).

En este estudio de susceptibilidad de Cándida Krusei fue sensible a la Anfotericina B, Clotrimazol, Miconazol y resistente a la Flucitosina, Ketoconazol, Itraconazol y Fluconazol. En un estudio realizado en Kenia y Brazil sobre la susceptibilidad antifúngica revela que Cándida Krusei fue resistente al Ketoconazol. Otro estudio se susceptibilidad indica que Cándida Krusei posee resistencia natural al fluconazol $(1,20)$. En un estudio realizado en Etiopía demuestra que Cándida Krusei fue $100 \%$ resistente al fluconazol y $33.3 \%$ a la flucitosina (22). Un estudio en Irak demuestra que Cándida Krusei es resistente al Fluconazol (28). 
Por otra parte, la susceptibilidad de Cándida Tropicalis fue susceptible a la Nistatina, Flucitosina, Ketoconazol, Clotrimazol, Miconazol, Itraconazol, y resistente a la Anfotericina B, Econazol y Fluconazol. Un estudio realizado en Irak revela que Cándida Tropicalis es resistente a Fluconazol e Itraconazol (28).

La susceptibilidad de Cándida Parapsilosis en este fue sensible a la Nistatina, Econazol, Miconazol, Itraconazol; posee sensibilidad intermedia a la Flucitosina, Ketoconazol y resistencia a la Anfotericina B, Voriconazol y Fluconazol

Existe una variación de prevalencia de Candidiasis encontrada en los distintos estudios, los factores que pueden atribuir esta variación es el número de muestras vaginales que cada autor trabajó en cada estudio, las características de la población y los distintos método de diagnóstico para la identificación, aislamiento de cada especie para cada estudio.

El aumento de resistencia a las especies de Cándidas se da por la terapia empírica antifúngica, ya las especies de Cándida pueden no ser susceptibles a los antifúngicos. Las pruebas de susceptibilidad son de mayor importancia ya permiten la seleccionar acerca de cuál es el antifúngico apropiado

\section{CONCLUSIONES}

$\mathrm{E}$ l presente estudio concluyó que la prevalencia de candidiasis vulvovaginal en mujeres embarazadas del Hospital Ángela Loayza de Ollague fue del $44.98 \%$.

Cándida Albicans fue la especie más común aislada en las mujeres embarazadas representando un $72 \%$, seguido de la especie No-Albicans Cándida Glabrata 19\%, Cándida Krusei 5\%, Cándida Tropicalis 3\% y Cándida Parapsilosis 1\%.
En la evaluación de la susceptibilidad a través del kit Integral System Yeast Plus obtuvimos que Cándida Albicans es susceptible a Anfotericina B, Flucitosina, Econaozol, Ketoconazol, Clotrimazol, Miconazol, Itraconazol, Voriconazol y Fluconazol y sensible a la Nistatina.

En Cándida Glabrata se obtuvo que es sensible a la Nistatina, Anfotericina B, susceptible al Econazol, Ketoconazol, Miconazol, Itraconazol, Voriconazol, y resistente al Clotrimazol, Flucitosina y Fluconazol.

En Cándida Krusei se obtuvo que es sensible a la Anfotericina B, Clotrimazol, Miconazol, susceptibles a la Nistatina, Voriconazol y resistente a la Flucitosina, Ketoconazol, Itraconazol y Fluconazol.

En Cándida Tropicalis es susceptible a la Nistatina, Flucitosina, Ketoconazol, Clotrimazol, Miconazol, Itraconazol y resistente a la Anfotericina B, Econazol y Fluconazol.

En Cándida Parapsilosis se obtuvo que es sensible a la Nistatina, Econazol, Clotrimazol, Miconazol, Itraconazol, intermedio a la Flucitosina, Ketoconazol y resistente a la Anfotericina B, Voriconazol y Fluconazol.

\section{Recomendaciones}

- Se debe evitar el uso de antifúngicos sin diagnóstico definitivo para evitar resistencia de los mismos.

- Las mujeres embarazadas deben realizarse controles para tratar a tiempo el diagnóstico temprano de candidiasis.

- Se debe mantener una correcta higiene personal y hábitos de aseos para evitar infecciones.

- Evitar ropa ajustada que ya aumentan la temperatura del área de la vagina y logran colonizar de mejor manera. 


\section{REFERENCIAS BIBLIOGRÁFICAS}

1. Espinoza D, Villaroel O M. Biomedicina 2016; 28:720-725

2. Jiménez R, Valle L, Sebastián J, Padilla ML Sánchez ML. Redalyc.org 2016; 16:32-42

3. Intriago-Rosado AM, Sarango-Intriago NE, Bodero-franco CF. Polo del conoc. 2017; 2(7):273-284

4. Zurita J. Bionatura. 2017; 2(3):344347

5. Soledad M, Rodríguez E, Vigezzi AP, Gonzaga M, Araújo DF, Oscar F, Vargas L, Abiega C, Pablo EC. Rev. Iberoam. Micol. Candidiasis vulvovaginal 2017; 34 (2):65-71

6. Ahmad SS, Ali FA. Int. J. MediPharm Res. 2015; 01(02):95-105

7. Aguilar G, Araujo P, Godoy E, Falcón M, Centurión MG. Instituto M; Cienc, I 2017; 15(3):6-12

8. Carmona-Lorduy M, Porto-Puerta I, Lanfranchi H, Medina-Carmona W, Werner L, Maturana S. Univ. y Salud 2017; 20(1), 82

9. Uzoh,CV et al. Adv. Life Sci. Technol. 2016; 41(400):54-58

10. Yadav, K.; Prakash, S. Glob. J. Med. Med. Sci. Full 2016; 4(1):108-116

11. Zapata Martínez JF, Pérez-Muñoz A, Tirado-Otálvaro AF, González JD, Velásquez SM. Enfermería Glob. 2018;17(50):86-106

12. Marleny Valencia Arredondo, W. A. Y.L. 2014; 31(2):133-144

13. Publica, M. de S. Diagnóstico y tratamiento de la infección vaginal en obstetricia; 2014

14. Altayyar IA, Alsanosi AS, Osman NA,
Ali I. Eur. J. Exp. Biol. 2016;6(3):25-29

15. Pfaller MR. Microbiologia médica, Edición; 2014

16. Makanjuola O, Bongomin F, Fayemiwo SJ. Fungi. 2018; 4(4):121

17. Arenas R. Micologia médica ilustrada; 2014

18. Elsilk SE, Ibrahem G, Shamma T. Amer SM. Egypt. Soc. Exp. Biol. 2015;11(2):207-216

19. Gerald S, Swaminathan KR, Devi M, Gerald S, Swathi C, Thomas BM. Int. J. Clin. Obstet. Gynaecol. 2017 2017; 1(2);37-39

20. Mtibaa L, Fakhfakh N, Kallel A, Belhadj S, Salah NB, Bada N, Kallel KJ. Mycol. Med. 2017

21. Akinbami Abidemi Nurat, Babalola Gbolahan Ola, Shittu Mujeeb Olushola, TAM. \& ASA. Int. J. Biomed. Res. 2015, 5 (2013): 518-522

22. Bitew Adane AY. Bitew Abebaw BMC Women's Heal. 2018: 1-10

23. Ekelozie, I.S., Chijioke, U.O., Obeagu, E. I. Int. J. Curr. Res. Biol. Med. 2018, 3:15-23

24. Samuel O, Ifeanyi O, Ugochukwu 0. Bioeng. Biosci. 2015; 3(2):23-27

25. S AR, Paul S, Kannan I. Int. J. Reprod. Contraception, Obstet. Gynecol. 2017; 6(2): 443-446

26. Mohammed, N. A.; Abdulbaqi, N. J.; Ajah, H. A. Int. J. ChemTech Res. 2017; 10(5): 844-857

27. Suárez P, Belloz, A.; Puelloz, M.; Youngz, G.; Duranz, M. 2018; 18(1)

28. Al-ruaby, K. J. W. Int. J. Sci. Eng. Res. 2016; 7(12):218-228

29. Tsega A, Damtie D, Unakal C. Int. J. Pharm. Heal. care Res. 2014; 2(4):15-23 